East African Medical Journal Vol. 80 No 10 October 2003 PRIAPISM IN SOUTHWESTERN NIGERIA

T.A. Badmus, FWACS, Consultant Surgeon, Department of Surgery, I. A. Adediran, FMCP, Consultant Haematologist, Department of Haematology, A.R.K. Adesunkanmi, FMCS, FWACS, Consultant Surgeon, I. A. Katung, MBBS, Surgical Registrar, Department of Surgery, Faculty of Clinical Sciences, College of Health Sciences, Obafemi Awolowo University, Ile-Ife, Osun State, Nigeria

Request for reprints to: Dr. T. A. Badmus, Department of Surgery, Faculty of Clinical Sciences, College of Health Sciences, Obafemi Awolowo University, Ile-Ife, Osun State, Nigeria

\title{
PRIAPISM IN SOUTHWESTERN NIGERIA
}

\author{
T.A. BADMUS, I.A. ADEDIRAN, A.R.K. ADESUNKANMI and I.A. KATUNG
}

\begin{abstract}
Objectives: To determine the aetiology, pattern of presentation, treatment regimen and outcome of management of priapism in our environment and to compare our findings with previous studies in this country and elsewhere.

Design: A 10-year retrospective study from January 1991 to December 2000.

Setting: Obafemi Awolowo University Teaching Hospital Complex, Ile-Ife, Nigeria.

Patients and methods: Hospital records of 16 patients managed for priapism over 10 years (January 1991 to December 2000) were analysed. Information extracted included the age, occupation, duration of symptoms, precipitating factors, past medical history, haemoglobin genotype, drug and social history, physical findings, treatment regimen, outcome of treatment, complications and duration of follow up. Eighteen patients were treated for priapism during the period but only sixteen case files available for analysis were reviewed in this study.

Results: The mean age of the 16 patients under review was 20.4 years (range: $2.5-38$ years). Thirteen patients $(81 \%)$ were single and $10(62.5 \%)$ were students. All the patients presented late with pain and woody hard penis with mean duration of eight days (range; 7 hrs-30 days). Eleven patients $(68.7 \%)$ had previous episodes of priapism. Fourteen patients $(87.5 \%)$ had sickle cell disease (SCD) and two $(12.5 \%)$ were psychiatric patients on oral chlorpromazine. Associated medical conditions include urinary tract infection, malaria, acute urinary retention, bone pain crises and acute psychosis. All the patients received initial conservative management. Six patients had needle aspiration with irrigation plus injection of $2 \mathrm{ml}$ of adrenaline solution $(1 \mathrm{ml} 1 / 1000$ adrenaline in $200 \mathrm{ml}$ saline) in both corpora cavernosa. One (16.7\%) out of the six patients achieved full detumescence with normal erection. The remaining five patients later had cavernotomy with full detumescence and normal erection in three $(60 \%)$ and weak erection in two (40\%). Eight patients had Cavernosa-glandular shunt, full detumescence and normal erection was achieved in five patients $(62.5 \%)$ while three $(37.5 \%)$ became impotent. Two of the three patients with impotence presented with the longest duration of symptoms (14 and 30 days respectively), while the third patient reported earlier after five days, but he had suffered more than six ( $>6)$ previous attacks of priapism. Duration of hospital stay was 3-10 days and the average duration of follow up was 80.7 weeks. Conclusion: Sickle cell disease account for $87.5 \%$ of priapism in our community. Late presentation and previous episodes of priapism, which are common features in most of these patients, are associated with poor prognosis with higher risk of impotence. Conservative management and aspiration with intracavernous adrenaline therapy appears ineffective in late case. However, good results obtained with surgery indicate that late presentation should not be a deterrent to surgical intervention. Surgeries in form of cavernotomy or cavernosa-glandular shunt, when carefully done, are effective and safe.
\end{abstract}




\section{INTRODUCTION}

Priapism is a clinical state in which there is persistent usually painful penile erection often in the absence of erotic psychic stimuli or a condition in which erection fail to subside despite orgasm. This is a urological emergency resulting from the disturbance of the normal regulatory mechanism controlling penile erection and flaccidity. Men at risk of developing priapism are patients with erectile dysfunction undergoing intracavernous form of therapy, sickle cell disease (SCD) patients, cocaine and marijuana users, psychiatry patients and accident victims $(1,2)$. This condition has long been recognised in areas where SCD is endemic (1), but relatively rare elsewhere until just over a decade ago when intracavernous agents such as papaverin and alprostadil were introduced in the treatment of erectile dysfunction. Since then, there has been increase in the number of men seeking treatment for priapism and this is currently held as the most common aetiological factor in western countries (2-4). The conversion to oral agents to treat erectile dysfunction was also observed to be associated with reduction in the number of men at risk of injection related priapism in these communities. While drug related priapism is held as the most common aetiological factor in these developed countries, this is most unlikely in many developing countries because intracavernous therapy has not become widely practiced.

Earlier report by Adeyokunnu, et al. (1), in 1981, and Adetayo and Osegbe (5), in 1994 identified SCD as the commonest cause of priapism in Lagos, Nigeria, whereas Aghaji(6), in 2000 identified local aphrodisiac as the commonest predisposing factor of priapism in Eastern Nigeria followed by SCD. This study was carried out at Obafemi Awolowo University Teaching Hospital complex, Ile-Ife, Nigeria, which serves the needs of rural and semi-Urban population of Osun, Ondo, Ekiti, and part of Kogi, Kwara, and Oyo states, all in the South western Nigeria. It was undertaken to determine the aetiology, pattern of presentation and outcome of treatments of priapism in our environment and to compare our findings with the previous local studies and those from the developed countries. It is hoped that this study will help to highlight problems associated with the management of this condition in developing societies, assist us and other practitioners in communities similar to ours, to improve on the management pattern, and help to increase public awareness to prevent late presentation and thereby reduce the morbidities resulting from priapism.

\section{MATERIALS AND METHODS}

The case files of patients who presented and managed for priapism at Obafemi Awolowo University Teaching Hospital Complex (OAUTHC), IIe-Ife, Nigeria, between January 1991 and December 2000 were reviewed in retrospect. Eighteen patients were treated for priapism during the period but only sixteen case files available for analysis were reviewed. Information extracted and analysed included age, occupation, duration of symptoms, precipitating factors, past medical history, haemoglobin genotype, drug, and social history, physical findings, treatment regimen, outcome of treatment and duration of follow up. Diagnosis was based on the history, clinical findings of tender woody hard penis involving the whole shaft, and the aspiration of dark viscous blood from the cavernous tissue.

All the patients received initial conservative treatment which consists of 50mg pethidine intramuscular injection, icecold pack, intravenous fluid therapy with $10 \mathrm{mg}$ diazepam injection inside fluid as slow infusion and then observed for detumescence over periods which ranged from 3-6hrs with vital signs monitoring. Fourteen patients $(87.5 \%)$ in whom tumescence persisted were later planned for emergency surgical intervention. Six patients (37.5\%) had needle aspiration using size $16 \mathrm{G}$ needle, with irrigation plus injection of $2 \mathrm{ml}$ of adrenalin solution $(1 \mathrm{ml} 1 / 1000$ adrenaline in $2000 \mathrm{ml}$ saline) in both corpora cavernosa after irrigation. One patient responded to needle aspiration and the remaining five (31.2\%) later had cavernotomy by making a single $5-10 \mathrm{~mm}$ lateral incision on the corpora cavernosa over the point of the needle puncture in the mid-shaft of the penis, through which dark, thick, viscous blood was squeezed out. Adopting Winter's procedure, eight patients $(50 \%)$ had Cavernosa-glandular shunt with the aid of Trucut needle passed through the glans penis. After surgery, patients were assessed daily for detumescence. All the sickle cell patients were jointly managed and followed up at the Haematology department of the same hospital. The average duration of follow-up was 80.7 weeks.

\section{RESULTS}

The age incidence of the patients lies within the first four decades of life (2.5-38 years), with a mean age of 20.4 years. Thirteen patients $(81.2 \%)$ were single and three patients $(18.7 \%)$ were married. Ten patients $(62.5 \%)$ were students, and one each $(6.25 \%)$ was a Teacher, Veterinary Doctor, Civil servant, Fisherman, pre-school child and unemployed mentally retarded patient. Fourteen patients $(87.5 \%)$ had sickle cell disease (SCD), 12 (75\%) were homozygous for sickle cell genes (Hb SS), one each $(6.2 \%)$ had heterozygous SC and AS genes. Only two patients (12.5\%) had normal haemoglobin AA, and both of them were on neurotropics for psychosis (Table 1). Eleven patients $(68.7 \%)$ had previous episodes of priapism ranging from one to six or more attacks, while five patients $(31.2 \%)$ had it as the first attack (Table 2).

All the patients presented late with persistent painful penile erection with mean duration of symptoms of eight days (range: 7 hrs-30 days). In nine patients $(56.2 \%)$ priapism started during sleep in the night while in seven patients $(43.7 \%)$, it started during daytime (Table 3). Apart from the underlying SCD in 14 patients, priapism was associated with other medical problems in $10(62.5 \%)$ patients, such as malaria in three $(18.7 \%)$, bone pain crisis in two $(12.5 \%)$, urinary tract infection, acute urinary retention and lobar pneumonia with septicaemia in one patient $(6.2 \%)$ each, 
and acute psychosis in two patients (12.5\%) both of whom were on chloropromazine tablets (Table 3 ). One patient each (6.2\%) had history of alcohol abuse and coitus eight hours before onset of priapism.

Table 1

Aetiology and the genotype of the patients

\begin{tabular}{llll}
\hline Aetiology & Total No. of Patients $(\%)$ & Genotype of the Patients & No. of Patients (\%) \\
\hline Sickle & & & \\
cell & $14(87.6)$ & SS & $12(75)$ \\
disease & & SC & $1(6.2)$ \\
& & AS & $2(12.2)$ \\
Drug & $2(12.5)$ & AA & \\
(Chlorpromazine) & & & $16(100)$ \\
\hline Total & $16(100)$ & & \\
\hline
\end{tabular}

Table 2

Previous attacks of priapism

\begin{tabular}{lcc}
\hline Group & No. of previous attacks & No. of patients $(\%)$ \\
\hline Patients without & None & $5(31.2)$ \\
previous attacks & One or more & $11(68.7)$ \\
& 1 & $4(25)$ \\
Patients with & 2 & $2(12.5)$ \\
previous attacks & 4 & $2(12.5)$ \\
& 5 & $1(6.2)$ \\
\multicolumn{1}{c}{ Total } & Several $(>6)$ & $2(12.5)$ \\
\hline \multicolumn{1}{c}{} \\
\hline
\end{tabular}

Table 3

Time of onset of priapism /associated medical conditions

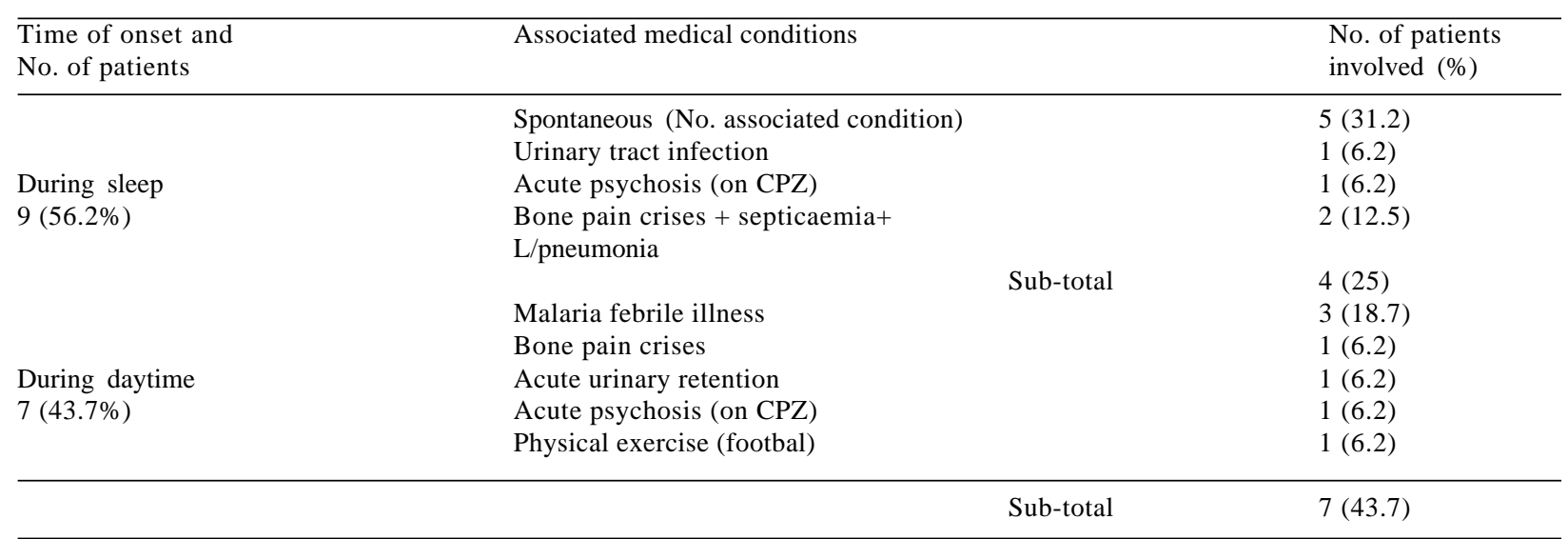

Note: These problems preceded the onset of priapism. $\mathrm{CPZ}=$ chlorpromazine 
Table 4

Outcome of treatment

\begin{tabular}{|c|c|c|c|c|c|c|c|}
\hline \multirow[t]{2}{*}{ Treatment modality } & \multirow[t]{2}{*}{ o. of cases $(\%)$} & \multicolumn{3}{|c|}{ Initial outcome } & \multicolumn{3}{|c|}{ Final outcome } \\
\hline & & $\begin{array}{c}\text { Persistent } \\
\text { Tumescencese }\end{array}$ & $\begin{array}{c}\text { Partial } \\
\text { Detumescence }\end{array}$ & $\begin{array}{c}\text { Full } \\
\text { Detumescence }\end{array}$ & $\operatorname{Impotent}(\%)$ & $\begin{array}{c}\text { Weak } \\
\text { Erection(\%) }\end{array}$ & $\begin{array}{c}\text { Normal } \\
\text { Erection }(\%)\end{array}$ \\
\hline $\begin{array}{l}\text { Conservative (IV fluid } \\
+10 \mathrm{mg} \text { slow Valium } \\
\text { infusion+ 50mg i.m } \\
\text { pethidine }\end{array}$ & $16(100)$ & $\begin{array}{c}14(87.5 \%) \\
\text { Later had } \\
\text { surgery }\end{array}$ & 0 & $2(12.5)$ & - & - & $2(12.5)$ \\
\hline $\begin{array}{l}\text { Needle Aspiration }+ \\
\text { irrigation }+ \text { intracavernous } \\
\text { injection of Adrenalin } \\
\text { solution }\end{array}$ & $6(37.5)$ & $\begin{array}{c}5(31.2 \%) \\
\text { Later had } \\
\text { Cavernotomy }\end{array}$ & 0 & $1(6.2)$ & - & - & $1(6.2)$ \\
\hline Cavernotomy & $5(31.2)$ & 0 & $\begin{array}{l}\text { 2(12.5) } \\
\text { Resolved fully } \\
\text { after } 3 \text { days }\end{array}$ & $3(18.7)$ & 0 & $2(12.5)$ & $3(18.7)$ \\
\hline Cavernosa-glandular shunt & $8(50)$ & 0 & $\begin{array}{l}2(25) \\
\text { Resolved fully } \\
\text { after } 3 \text { days }\end{array}$ & $6(75)$ & $3(18.7)$ & 0 & $5(31.2)$ \\
\hline $\begin{array}{l}\text { Overall results of all } \\
\text { patients }(\%)\end{array}$ & $16(100)$ & 0 & $4(25)$ & $12(75)$ & $3(18.7)$ & $2(12.5)$ & $11(68.7)$ \\
\hline
\end{tabular}

Four patients (25\%) presented on the day of attack, within 11 hours of onset; prognosis was good in all of them with full detumescence and normal erection. One $(16.7 \%)$ out of six patients who had needle aspiration and irrigation with adrenaline solution achieved full detumescence with subsequent normal erection. The remaining five patients $(31.2 \%)$ had cavernotomy; there was full detumescence in three patients $(60 \%)$ and initial partial detumescence in two patients $(40 \%)$, which resolved fully three days after surgery. Three $(60 \%)$ patients subsequent achieved normal erection while two (40\%) achieved weak erection (Table 4). Eight patients had Cavernosa-glandular shunt, $6(75 \%)$ had full detumescence with subsequent normal erection in five patients $(62.5 \%)$ and impotence in one $(12.5 \%)$, while two patients (25\%) initially had partial detumescence that resolved fully four days after surgery, both became impotent (Table 4). Two of the three patients with impotence presented with the longest duration of symptoms. The third patient with impotence presented relatively earlier after five days, but he had suffered more than six $(>6)$ previous attacks of priapism. apart from minimal blood loss, no major complication was recorded in all the patients. The duration of hospital stay was 3-10 days and the average duration of follow up was 80.7 weeks.

\section{DISCUSSION}

Priapism was named after Priapos, which paradoxically is a mythical Greek god of fertility. It is a urological emergency, which present with persistent often-painful penile erection that is not associated with sexual stimuli. The erection usually spares the glans penis and the corpus spongiosum and many cases
(>37\%) are believed to be idiopathic in origin $(7,8)$. There are two main varieties, the high flow nonischaemic type, which is painless and arterial in origin, and the low flow ischaemic type, which is painful and venous in origin. The former is rare and is usually secondary to perineal trauma leading to arteriovenous fistula $(9,10)$, while the latter is a recognised complication of SCD that is common in areas where SCD is endemic $(1,11)$ and this accounted for $87.6 \%$ of cases in this study. Elsewhere, the low flow variety is often secondary to thrombosis of the prostatic venous plexus, and less frequently it is due to leukaemia, secondary malignant deposit, spinal cord injury or idiopathic in origin $(7,11$ 13). Other rare causes of priapism include hypercoagulability states such as system lupus erythematosus and nephrotic syndrone, urothelial malignancies, paraneoplastic syndromes and various drugs like sedatives, $\square$ adrenergic agents, ketamine hydrochlorate, anticoagulant (heparin), prostaglandin $\mathrm{E}_{1}$, papaverin, phentolamin and psychotropic drugs like chlorpromazine $(3,4,13-15)$. Priapism is usually total as occurred in all the cases under review, but it can rarely be partial or segmental $(6,17)$. Priapism can also be recurrent and this accounted for $69 \%$ of the cases in this study.

Though all the patients in this study were male, clitoral priapism has also been documented in women (18). Priapism can occur in any age group but rarely in children except when it complicates SCD as witnessed in this study where children accounted for $37.5 \%$ of the cases. Priapism has been shown to complicate SCD in Nigerian children $(1,5)$ same with other studies from outside Nigeria (11). The age incidence 2.5-38 years observed in this series is similar to the findings by 
Adetayo et al (5) among SCD patients in Lagos, Nigeria. This result indicates that priapism is prevalent in our community in the first four decades of life, the peak periods being the first and the fourth decades. This is close to the findings of Ochoa and Hermida(7) who observed the highest incidence of priapism in the age range of 15-40 years.

All patients under review presented late with persistent painful penile erection, with mean duration of eight days (range $7 \mathrm{hrs}-30$ days). Late presentation for medicare is a common problem in our environment and it is largely due to ignorance and poverty. Benchekroun et al (8) in their review also observed late presentation with mean time to consultation of eight days (range 1-28 days) (8). Most authors believe that the risk of impotence complicating priapism rise substantially with the duration of symptoms before the initiation of treatment. Some believe that late intervention especially after a critical period of six hours of onset can cause ischaemia, which can lead to irreversible fibrotic changes in the cavernous tissue (3). Contrary to this view, Pohl et al (19) who examined prognosis in each of the first five days of duration of priapism showed that the interval between the onset of priapism and the initiation of specific treatment is not of any importance in the first five days because the incidence of impotence is not increased by this delay. He maintained that $65 \%$ still regained potency when intervention took place after five days, and $40 \%$ after 10 days of onset. In this study $11(68.7 \%)$ out of 16 patients regained potency (Table 4 ), and all of them presented within eight days of symptoms. Two patients with the longest duration of symptoms (14 and 30 days respectively) became impotent. The third patient with impotence in this series presented relatively earlier, after five days of onset of symptoms, but he had suffered more than six previous episodes of priapism.

This review like the earlier reports in Nigeria $(1,5)$, identified SCD as the most common aetiological factor of priapism in our environment, which accounted for $87.5 \%$ of cases in this review. Contrary to this, priapism is most frequently secondary to intracavernous injection of vasoactive agents for treating or diagnosing erectile dysfunction in western countries $(2,20)$. The report of epidemiological survey in Netherlands by Elands et al. (21), showed that SCD accounted for one in five cases (20\%) of priapism, while deHoll, et al (22), in Virginia, USA; also reported 9.1\%. In the Eastern Nigeria, SCD was second to a local aphrodisiac as the most common cause of priapism (6), which indicates a slight regional difference in the commonest cause of priapism among Nigerians. The aetiological difference noticeable between Nigeria and the Western countries appear to be a reflection of the high incidence of SCD in our community, and partly because intracavernous therapy has not become very popular in the treatment of erectile dysfunction in our community. Many Nigerians are too shy to seek treatment for impotence in public hospitals.
Vaso-occlusive crisis, common in SCD can predispose to low flow ischaemic priapism, though it is believed that the high flow priapism also exists in SCD patients (23). In this series, $11(68.7 \%)$ patients had priapism associated with other problems while in five $(31.2 \%)$ patients. It was spontaneous without association with other medical problems (Table 3). Most incidences of priapism occur during nocturnal penile tumescence, which was observed in nine patients $(56.2 \%)$ in this series (Table 3 ). This is due to smooth muscles relaxation that occurs during sleep causing arteriolar and sinusoidal dilatation with compression of intersinusoidal and subtunical venular plexus, leading to increased blood flow into penis with reduction in the outflow (24). Besides muscles relaxation during sleep, decrease in blood pressure and heart rate, which is known to occur in NREM sleep (25), can increase venous stasis, which in these patients already at risk of vaso-occlusive crises can predispose to venous thrombosis and priapism.

This review, like earlier reports, confirmed that sexual intercourse is not aetiologically linked to priapism, as only one patient $(6.2 \%)$, had sexual intercourse eight hours before the onset of symptoms. The rest $(93.8 \%)$ had many episodes that were not sexually related. It is therefore not a surprise that most patients $(93.8 \%)$ were single while only one patient $(6.2 \%)$ was married. Other social factors such as cigarette smoking habit and alcohol abuse also appeared to have no aetiological link with priapism in our community as only one $(6.2 \%)$ of these patients indulged in alcohol and none of them indulged in smoking cigarettes.

Although diagnosis in this series was clinical, based on symptoms and signs and the aspiration of dark viscous blood from the cavernous tissue (26), when available colour doppler ultrasound is the most useful diagnostic tool (27). Gasometry of cavernous blood and selective arterial angiography have also been found very useful in the diagnosis of priapism due to trauma (28).

Treatment of priapism depends on the aetiology, and it can be conservative or surgical. The high flow variety due to artero-venous fistula formation are usually successfully treated by selective arterial embolisation or ligation of the feeding artery (29), though its treatment can also be conservative and intervention can be delayed for some days $(2,9)$. This is because the risk of ischaemia in this type of priapism is minimal and perhaps, the fear that surgery can be potentially damaging makes conservative approach preferable to some especially for paediatric patients. The report by Pohl et al. (19), which confirmed no prognostic difference in the first five days of onset of priapism, also justifies delay in surgical intervention.

The low flow ischaemic priapism requires rapid resolution and is usually managed surgically, by creating shunt to drain blood away from the corpora cavernosa. Various shunting procedures, which include cavernosaglandular, shunt spongiocavernosa shunt and 
cavernosaphenous shunt, have been described. Cavernosaglandular, shunt originally described by Ebbehoj (30), in 1975, was modified by Winter (31) in 1976 using a trucut biopsy needle and by El-Ghoreb in 1981 with open surgical removal of small piece of tissue where corpora cavernosa unite with the glans penis (32). Conservative management also has a place in early presentation. Oral or intracavernous etilefrine, sedatives and aspiration with intracavernous injection of vasoactive agents or methylene blue, a guanylate cyclase inhibitor, have all been found useful $(2,4,20)$. In this series, four patients $(25 \%)$ presented within 11 hours of onset, two of them responded to conservative medical management and the remaining two had Cavernosa-glandular shunt, with full detumescence and normal erection in all the four patients, thus emphasizing the need for early presentation and normal erection in all the four patients, thus emphasizing the need for early presentation and prompt intervention to achieve good prognosis in this condition. Only one out of six patients $(16.7 \%)$ responded to needle aspiration with irrigation and injection of adrenaline solution (Table 4). This agrees with the observation by Keskin, et al (20), that intracavernous adrenalin is useful only in priapism of short duration. Ochoa et al (7) have also shown that intracavernous therapy is best for drug-induced priapism.

Failure of initial conservative measures necessitated surgical intervention in the form of cavernotomy and Cavernosa-glandular shunt, with good results in this study. Five $(62.5 \%)$ out of eight patients with Cavernosaglandular shunt achieved full detumescence with normal erection while three became impotent. In those with cavernotomy, three $(60 \%)$ out of five patients achieved full detumescence with normal erection, while two (40\%) developed weak erection. On the whole, five out of thirteen patients that had surgery developed erectile dysfunction (three patients with impotence and two with weak erection). This indicates that the failure rate of surgery in this review was $38.5 \%$, despite late presentation. This results are close to findings from the analysis by Pohl et al. (19), earlier mentioned, and the reports of Benchekroun et al. (8), who recorded a success rate of $70 \%$ with Cavernosa-glandular shunt and overall failure rate of $37 \%$. Winter's procedure was adopted in carrying out Cavernosa-glandular shunt in this series (29). The authors prefer this procedure because it is simple, effective and it is hoped that the risk of fibrosis complicating the procedure will be minimal.

Application of ice cold pack as part of the conservative management in these patients was aimed at causing vasoconstriction to reduce blood flow to the engorged organ. Better understanding in the pathophysiology of vaso-occlusive crises has however shown that cold could further aggravate stasis and sickling in SCD patients, which can aggravate low flow priapism. This could have contributed to the poor results observed with conservative management in this study. However, the overall results obtained from surgery in this review shows that corpora cavernosa surgeries (cavernotomy or Cavernosa-glandular shunt), where carefully done, are not as dangerous as hitherto thought Colombani et al(11), who emphasised the safety and effectiveness of cavernosa puncture without the risk of fibrosis, pointed out that subsequent minor recurrence could be a later cause of fibrosis and impotence. Contrary to this view is the school of thought, which believes that patients who suffered previous episodes with spontaneous relief have good prognosis(19).

This review being a retrospective study, it is difficult to determine whether other factors apart from ignorance and poverty contributed to late presentation in these patients. A further study will be needed to answer this question. What can be said for now is that ignorance and poverty, which have been identified locally as major causes of patients delay to our hospitals, coupled with the belief in the traditional and spiritual healers may play a role. As in other developing countries, traditional healers still constitute the first place of call for medical care in our community. Health education needs to be intensified to increase the awareness on the morbidity associated with priapism in the general population. More importantly, regular adequate hydration and proper care of sickle cell patients and appropriate counselling to all, will go a long way in reducing the incidence of priapism amongst patients with SCD and priapism prone individuals.

\section{REFERENCES}

1. Adeyokunnu, A. A., Lawani, J.O. and Nkposong, E.O. Priapism complicating sickle cell disease in Nigerian children. Annals Tropical Paediat. 1981; 1:143-147.

2. Pautler, S.E. and Brock, G.B. Priapism. From Priapus to the present time. Urol Clin North Am. 2001; 28:391-403.

3. Hora, M. and Ouda, Z. Priapism. Cas Lek Cesk. 1999; 138:131-135.

4. Martinez, P.F., Hoang-Boehm, J., Weiss J. et al. Methylene blue as a successful treatment alternative for pharmacologically induced priapism. Eur Urol. 2001; 39: 20-23.

5. Adetayo, F.O. and Osegbe, D.N. Priapism: Results of surgical treatment in sicklers and non-sicklers at the Lagos University Teaching Hospital. Nigerian Postgraduate Med. J. 1994; 1:9-12.

6. Aghaji, A.E. Priapism in adult Nigerians. Brit. J. Urol. Int. 2000; 85:493-495.

7. Ochoa, U.O. and Hermida, P.J.A. Priapism: Our experience. Arch Esp Urol. 1998; 51:269-276.

8. Benchekroun, A., Lachkar, A., Soumana, A., et al. Priapism in adults: 16 cases. Ann Urol (Paris). 1998; 32:103-106.

9. Moscovici, J., Barret, E., Galinier, P., et al. Post-traumatic arterial priapism in the child: a study of four cases. Eur. J. Pediatr. Surg. 2000; 10:72-76.

10. Goto, T., Noguchi, A., Hamamoto, Y., et al. A case of traumatic priapism. Hinyokika Kiyo. 2000; 46:907-910.

11. Colombani, J.F., Peluchon, P., Elana, G. and Delatre, P. Priapism in a sickle cell prepuberal child. Eur. J. Pediatr. Surg. 2000; 10:68-71.

12. Morano, S.G., Latagliata, R., Carmosino, I., Girmenia, C., Dal Forno, S. and Alimena, G. Treatment of long-lasting 
priapism in chronic myeloid leukemia at onset. Ann. Hematol. 2000; 79:644-645.

13. Chan, P.T., Begin, L.R., Arnold, D., et al. Priapism secondary to penile metastasis: a report of two cases and a review of the literature. J. Surg. Oncol. 1998; 68:51-59.

14. Munoz, V.D., Rebassa, L.M., Conte, V.A. and Ozonas, M.M. Low-flow priapism associated with systematic lupus erythematosus and nephrotic Syndrome. Arch. Esp. Urol. 2000; 53:929.

15. Compton, M.T. and Miller, A.H. Priapism associated with conventional and typical antipsychotic medications. Am. J. Clin. Psychiatry. 2001; 62:362-366.

16. Lewis, J.H., Javidan, J., Keoleian, C.M. and Shetty, S.D. Management of partial segmental priapism. Urology. 2001; 57:169.

17. Schneede, P., Schmeller, N., Muller-Lisse, U.G., Reiser, M.F. and Hofstetter A.G. Partial priapism. Case report and review of the literature of diagnostic and therapeutic measures. Urologe A. 1999; 38:179-183.

18. Medina, C.A. Clitoral priapism: a rare condition presenting as a cause of vulvar pain. Obstet. Gynecol. 2002; 100:10891091.

19. Pohl, J., Pott, B. and Kleinhans, G. Priapism: a three-phase concept of management according to aetiology and prognosis. Brit. J. Urol. 1986; 58:113-118.

20. Keskin, D., Cal, C., Delibas, M., et al. Intracavernosal adrenalin injection in priapism.. Int. J. Impot. Res. 2000; 12:312-314

21. Eland, I. A., Van der Lei, J., Stricker, B.H. and Sturkenboom, M.J. Incidence of priapism in the general population. Urology. 2001; 57:970-972

22. deHoll, J.D., Shin, P.A., Angle, J.F. and Steers, W.D.
Alternative approaches to the management of priapism. Int. J. Impot. Res. 1998; 10:11-14.

23. Ramos, C.E., Park, J.S., Ritchey, M.L. and Benson, G.S. High flow priapism associated with sickle cell disease. J. Urol. 1995; 153:1619-1621.

24. Ignarro, L.J., Bush, P.A., Buga, G.M, et al. Nitric oxide and cyclic GMP formation upon electrical stimulation cause relaxation of corpus cavernousal smooth muscles. Biochem Biophy Res Comm. 1990; 179:843-850.

25. Czeisler, C.A. and Richardson, G.S. Disorders of sleep and circadin rhythms. Harrison's Principles of Internal Medicine, International edition, 14th edition. The McGraw-Hill Companies, Health Profession Division. USA. 1998.

26. Lehmann, K. Priapism. Ther. Umsch. 1998; 55:377-379.

27. Secil, M., Arslan, D., Goktay, A.Y., Esen, A.A., Dicle, O. and Pirnar, T. The prediction of papaverine induced priapism by color Doppler sonography. J. Urol. 2001; 165:416-418.

28. Goto, T., Yagi, S., Matsushita, S., et al. Diagnosis and treatment of priapism : experience with 5 cases. Urology. 1999; 53:1019-1023.

29. Colombo, F., Lovaria, A., Saccheri, S., et al. Arterial embolisation in the treatment of post-traumatic priapism. Ann. Urol. 1999; 33:210-218.

30. Ebbehoj, J. A new operation for priapism. Scand. J. Plastic Reconstructive Surgery. 1975; 6:241-242.

31. Winter, C.C. Priapism cured by creation of fistula between glans penis and corporal cavernosa. J. Urol. 1978; 119:227228.

32. El-Ghoreb, M. M., Ercole, C.J, Pontes, J.E. and Pierce, J.M., Jr. Changing Surgical concepts in the treatment of priapism. J. Urology. 1981; 125:210-211. 